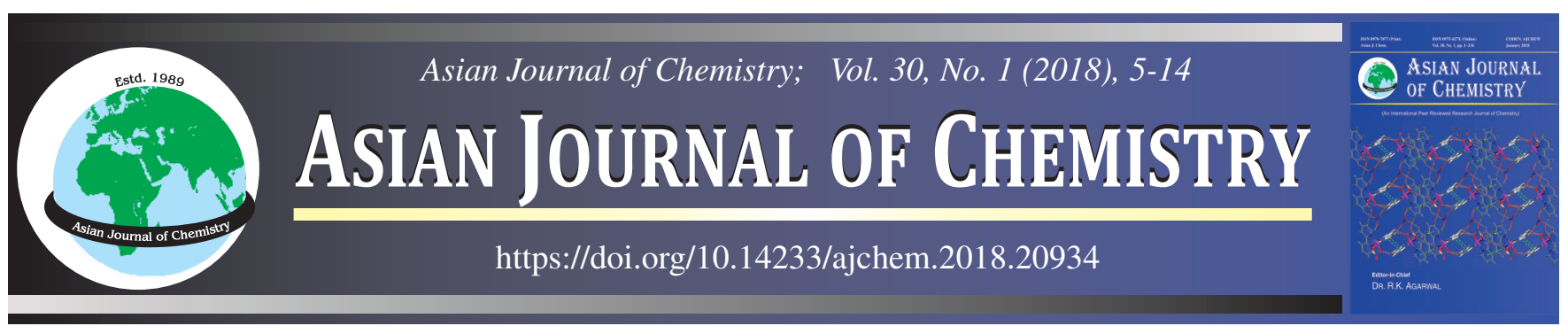

REVIEW

\title{
Art of Synthesis of Desired Polymorphs: A Review
}

\author{
Runjhun TAndon $^{1}$, Nitin TAndon $^{1, *}$, NeElima Gupta $^{2}$ and RaAkhi Gupta ${ }^{3}$
}

\author{
${ }^{1}$ Department of Chemistry, Lovely Professional University, Jalandhar-Delhi G.T. Road, Phagwara-144 411, India \\ ${ }^{2}$ Department of Chemistry, Rajasthan University, J.L.N. Marg, Jaipur-302 004, India \\ ${ }^{3}$ Department of Chemistry, IIS University, Jaipur-302 020, India \\ *Corresponding author: E-mail: tandonnitin12004@gmail.com
}

Received: 22 July 2017;

Accepted: 29 September 2017;

Published online: 30 November 2017;

AJC-18639

\begin{abstract}
Polymorphism plays an important role in drug solubility and availability. The study of the polymorphism of active pharmaceutical ingredients has become crucial for the synthesis of active pharmaceutical ingredients. This review provides observations, synthetic methods and characterization techniques for polymorphs using the latest analytical techniques. The desired polymorph can be obtained by choosing the proper nucleation mechanism.

Keywords: Polymorphism, Amorphous, Crystalline, Nucleation, Crystallization.
\end{abstract}

\section{INTRODUCTION}

Polymorphism begins with nucleation. The nucleation mechanism can be divided into two main categories, homogeneous and heterogeneous [1]. Homogeneous nucleation rarely occurs in large volumes (greater than $100 \mu \mathrm{L}$ ), as random impurities in solution can induce nucleation [2]. The surface or interface of a composition and/or structure that is different from the crystallizing solute can serve as the nucleation substrate by decreasing the energy barrier for the formation of a nucleus that can grow into a mature crystal. Nucleation promoted by crystals in a crystallizing solute is known as secondary nucleation. These mechanisms have been thoroughly described by Mullin [3] and Myerson [4]. Nucleation mechanisms are of great utility in controlling the nucleation and transformation of polymorphs and solvents, isolating metastable solid phases in confined spaces [5], diverting the nucleation of polymorphs using solid substrates to template certain crystal structures [6] and controlling transformations during the dissolution of metastable solid phases [7]. In recent years, several new techniques have been developed for nucleation. Additionally, some recent developments in crystallization techniques also contribute towards this goal [8-12]. Different techniques for the generation of polymorphs are presented here.

Single solvent crystallization: The crystallization technique is designed using parameters such as temperature, solvent range, concentration, etc. In this method, a compound is dissolved in a single solvent and a clear solution is obtained at room temperature or higher. The compound is then crystallized using gradual cooling (the hot crystallizing solution is brought to room temperature slowly and then cooled) or sudden cooling (the crystallizing solution is cooled rapidly). If crystals do not grow upon cooling, then crystallization is induced by scratching with a glass rod or the addition of a seed. The solvent is selected with care and those that are likely to be encountered during formulation or processing are preferred. Various factors that affect crystallization by this technique are a) solvent polarity, b) concentration, c) temperature (including cooling rate), d) seeding and e) agitation. The main reason for the variation in crystallization in different solvents is the difference in polarity of these solvents. Molecules in solution often tend to form different types of hydrogen-bonded aggregates. The concentration of the solution also plays an important role in the generation of crystals, where the better the concentrate, the better the crystallization. Suzuki [13] reported that the $\alpha$-form of inosine can be easily crystallized from water, whereas the $\beta$-form requires seed crystals. Seeding is often used to isolate the desired morph; for example, Form I of atorvastatin calcium always requires seed crystals to obtain the pure morph. The quantity of seed added varies from compound to compound, ranging from a pinch upto $1 \%$. Agitation also affects crystallization, where fast agitation results in metastable morphs with smaller particle sizes and slow agitation results in thermodynamically stable morphs with larger particle sizes.

A commonly used crystallization technique involves controlled temperature change. Slow cooling of a hot saturated 
solution can be effective for producing crystals if a compound is soluble at higher temperatures, whereas slow warming is applied to compounds soluble at higher temperatures. One of the possibilities of crystallization is to heat the solution to boiling, filter the undissolved solute and then cool the filtrate. It has been observed that high boiling solvents are useful for obtaining metastable polymorphs. Behme and Kensler [14] reported that in the crystallization of buspirone hydrochloride below $95{ }^{\circ} \mathrm{C}$, a polymorph with a lower melting point was obtained, whereas during crystallization above $95^{\circ} \mathrm{C}$, a new polymorph with a high melting point was obtained. The low melting point form of buspirone can be converted to the high melting point form by recrystallization in xylene.

Both the cooling rate and initial concentration influence the properties of polymorphs A, B, C and E isolated from stearic acid, as reported by Kaneko et al. [15]. In this case, only Garti et al. [16] reported a correlation between the polymorphs isolated and the extent of solvent-solute interactions. Sudden cooling mostly results in precipitation of the metastable forms.

Oharriz et al. [17] reported the effect of the polarity of the solvent on the nature of the final polymorph isolated. Form III of diflunisal was obtained from polar solvent, whereas Forms I and IV were obtained from non-polar solvents. Wu et al. [18] isolated Form I of moricizine hydrochloride from polar solvents such as acetone, ethanol, acetonitrile, etc. whereas the use of methylene chloride or a methylene chloride/ethyl acetate mixture resulted in Form II.

Multi-solvent crystallization: If the compound is not soluble in a single solvent or the desired polymorphic transformation is not obtained, a mixture of solvents can be used. This method employs the dissolution of the compound in a mixture of two or more solvents, followed by crystallization through gradual or sudden cooling. This system usually depends on the solubility of the compound in the different solvents. Often, a solvent system is selected in which the solute is more soluble in the component with higher vapour pressure. Because the two solvents evaporate at different rates, as the volume of solution is reduced, the composition of the solvent mixture changes. Crystallization can be designed by choosing a variety of solvent systems in which the compound is soluble, thereby increasing or decreasing the polarity of this solvent system. Mixing ethanol and water makes the system polar, whereas mixing ethanol and ethyl acetate makes the solvent system less polar. Kitamura et al. [19] illustrated that Form A and Form B of L-histidine was crystallized using an ethanol-water mixture with a volume fraction of 0.2 and 0.4 , respectively. In this particular example, the transformation rate for conversion of Form B to Form A decreases with the ethanol concentration. Form I of dehydroepiandrosterone was obtained by recrystallization from a mixture of warm ethyl acetate, acetone and acetonitrile [20]. The new triclinic form B of hydroxyprogesterone caproate was synthesized from slurry in multiple solvent [21].

Antisolvent addition: A new polymorph of a given compound can be obtained by dissolving the compound in a single solvent, followed by the addition of an antisolvent with properties opposite to the previous solvent. Normally, the antisolvent is a solvent in which the compound has either very low or no solubility. One of the key points in this crystallization method is to not use a large volume of antisolvent. Large volumes can be used when precipitation of the material is required to generate the metastable forms. One of the experimental techniques for this type of crystallization is heating the solution and then pouring it into the antisolvent or over cracked ice. For example, the amorphous form of atorvastatin was reported to be obtained by dissolving the drug in tetrahydrofuran with cyclohexane as the antisolvent, whereas Form I was obtained by dissolving the drug in methanol and precipitating it with water [22,23]. Otsuka et al. [24] reported the isolation of Form $\mathrm{B}$ of phenobarbital by adding a saturated methanolic solution of the compound drop-wise into water, whereas Form E was obtained by replacing methanol with dioxane. The $\alpha$-form of indomethacin has been prepared by dissolving the compound in methanol and precipitating with water [25].

Complete removal of solvent: This technique involves the complete removal of solvent from solution by evaporation at normal pressure or under vacuum and is commonly used to obtain the amorphous form. If the solvent occupies channels in the crystal structure, the structure remains intact upon evaporation and a solvate is formed. On the other hand, when the solvent is strongly bonded to the solute molecules, the structure collapses upon evaporation, resulting in an amorphous powder. The complete removal of solvent results in the amorphous form. However, the problems, such as the presence of organic volatile impurities (solvents), have to be dealt with, according to FDA guidelines. This technique has been used to obtain anhydrous raffinose from pentahydrate [26], erythromycin from dihydrate [27] and tranilast from monohydrate [28]. Form II of dehydroepiandrosterone was obtained by the evaporation of solvent under vacuum, while Form B of fosinopril sodium was isolated by the rapid drying of its solution [29].

Grinding: Grinding is also an established method for polymorphic transformations and has been used for sulfathiazoles, barbital, cephalexin, indomethacin, phenylbutazone and chloramphenicol. Although grinding of a compound results in an amorphous substance, different polymorphic forms can be obtained, as reported in the case of chloramphenicol, where the metastable Forms B and C were transformed into the stable Form A upon grinding at room temperature [30]. The grinding temperature affects the polymorphic transformation; e.g., indomethacin gave a non-crystalline solid by grinding at $4{ }^{\circ} \mathrm{C}$, whereas metastable Form A was obtained by grinding at $30^{\circ} \mathrm{C}$. Caffeine Form II has been reported to convert into Form I by grinding [31]. This technique involves decreasing the particle size of the compound using a grinder. The amorphous form of ranitidine has been obtained by grinding or cryomilling [32].

Lyophilization: Lyophilization, or freeze-drying, involves freezing the material, followed by reducing the surrounding pressure to allow frozen water in the material to sublimate. This technique is particularly useful for compounds that decompose in the presence of moisture but are stable as dry solids. This technique results in the complete removal of solvent, especially water and is used to obtain the amorphous form. Lyophilization usually has three stages, freezing, primary drying and secondary drying. To obtain amorphous materials, rapid freezing is employed to avoid crystallization. The primary 
drying phase involves the sublimation of frozen water or the vaporization of another solvent. This step is carried out by reducing the pressure in the chamber and supplying heat to the product. The secondary drying phase consists of the desorption of moisture from the solvent. Rapid freezing of a methyl $p$-hydroxybenzoate solution containing $\alpha$-cyclodextrin and benzoate/cyclodextrin in a ratio of 0.33 gives the amorphous form after freeze-drying. $\beta$-Cyclodextrins have been isolated in the amorphous form by lyophilization. Aspirin [33], ketoprofen [34] and naproxen [35] have also been isolated using this technique.

Sublimation: Sublimation is the process of the transition of a substance from the solid phase to the gas phase without passing through an intermediate liquid phase. The polymorphic modification is affected by the sublimation temperature. Unstable crystals are preferentially formed at lower temperatures, while at higher temperatures, stable forms are obtained. This technique is applicable only to thermally stable compounds. One of the best methods for obtaining a good sublimate is to spread the material over a portion of a half-slide in a petri dish and cover it with a glass. Heat is applied to the system and when the sublime is well formed, the cover glass is removed to a clean slide for examination. It is also possible to form good crystals by sublimation from one microscopic slide to a second suspended above it. The upper slide is also heated, so that the temperature of the suspended slide is below the lower slide. Cooling of the cover slip by placing drops of various low boiling solvents on the top surface causes condensation of the more unstable morphs. The crystals of various modifications thus obtained can be used as seed for solution phase crystallization of larger quantities. This is a very good technique to grow single crystals of certain morphs. In this technique, the compound undergoes a phase change from solid to gas and then back to solid. Form I of 9,10-anthraquinone-2-carboxylic acid was obtained as needle-like crystals by sublimation above $250^{\circ} \mathrm{C}$ [36]. This technique has also been used for the purification of polymorphs of theophylline [37]. Vacuum sublimation has been reported to produce new stable morphs of 1,3-dimethyluracil and malonamide [38].

Crystallization from the melt: In accordance with Ostwald's rule, cooling the melts of polymorphic substances often yields the least stable modification first, which subsequently rearranges into stable forms. Since the metastable form has a lower melting point, super-cooling is necessary for crystallization. After melting, the system must be super-cooled below the melting point of the metastable form and at the same time, the crystallization of the more stable form or forms must be prevented. Quench cooling of the melt results in the amorphous form, which is usually obtained by cooling the melt so quickly that crystallizing nuclei do not have sufficient time to grow. The liquid remains a fluid below its normal freezing point. As cooling continues, the viscosity of the liquid continues to increase and finally, a glassy stage is obtained, which is the amorphous form. Caffeine Form I is obtained by heating Form II at $180{ }^{\circ} \mathrm{C}$ for $10 \mathrm{~h}$. Yoshioka et al. [39] reported that the amorphous form of indomethacin was obtained at $40{ }^{\circ} \mathrm{C}$, whereas mixtures of other morphs were obtained between 50 and $60{ }^{\circ} \mathrm{C}$.
Vapour diffusion: This technique is particularly useful for the preparation of single crystals for crystallographic analysis. In this method, the substance is dissolved in a solvent and this solution is kept in another larger vessel containing a small amount of a miscible, volatile antisolvent. The larger vessel, often a desiccator, is then tightly closed. As solvent equilibrium is approached, the antisolvent diffuses through the vapour phase into the solution and saturation or supersaturation is achieved (Fig. 1). Crystals of human serum albumin have been successfully grown in a variety of gels using crystallization conditions equivalent to those utilized in the popular hanging-drop vapour-equilibration method [40].
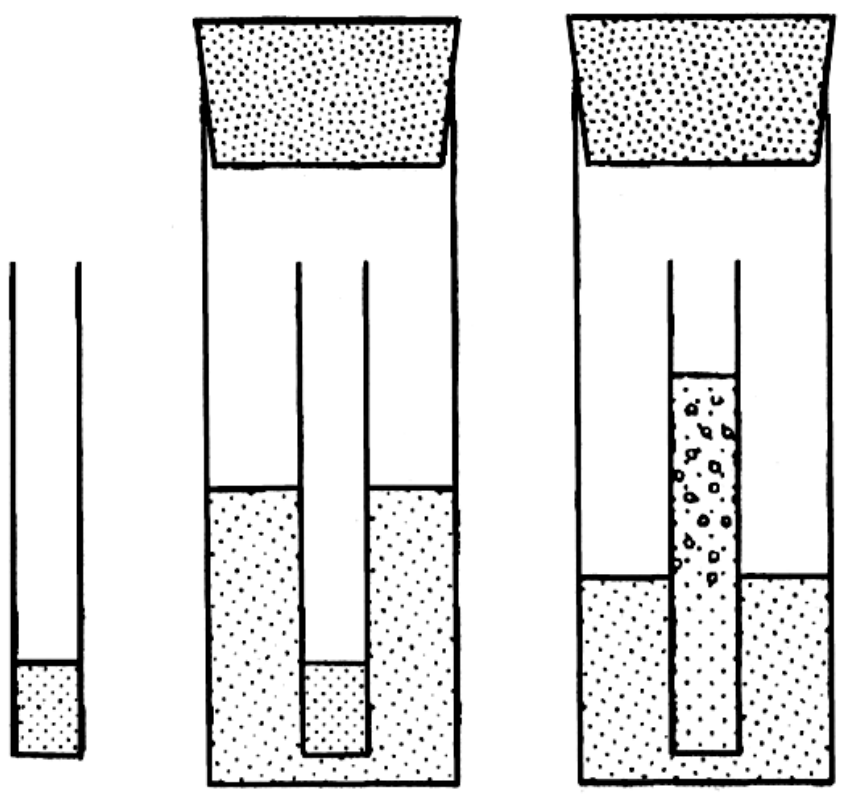

Fig. 1. Vapour diffusion method

Spray drying: Spray drying is a commonly used technique to dry heat-sensitive pharmaceuticals and change the physical form of materials for use in tablets and capsules and to encapsulate solid and liquid particles. Spray drying mostly results in the formation of amorphous powder and is used for heatsensitive substances. Spray drying is also the most commonly used technique in food processing [41]. In this technique, a liquid feed stream is first atomized for maximal air spray contact. The particles are dried in the air stream in seconds, owing to the high surface area that contacts the drying gas. Particles made by this technique are spherical in shape and free flowing. Polymorphs of lactose [42], digoxin [43] and 9,3-diacetyl-midecamycin [44] have been obtained from aqueous solutions of the respective compounds using the spray drying technique. The amorphous forms of cefazolin sodium, $\alpha$-lactose monohydrate [45] and furosemide [46] have been isolated using the spray drying technique.

Precipitation of acidic or basic substances by a change in pH: Many drugs fall in the category of weak acids or bases. Their salt forms are much more soluble in water. The addition of acid to an aqueous solution of a soluble salt of a weak base or upon the addition of alkali to an aqueous solution of a salt of a weak acid results in crystallization. In this technique, the level of super-saturation is carefully controlled; for example, 
the water-soluble salt of a weak acid is precipitated with a base and vice versa. Iopanoic acid was dissolved in $0.1 \mathrm{~N} \mathrm{NaOH}$, adjusting the $\mathrm{pH}$ to 12.5 and $0.1 \mathrm{~N} \mathrm{HCl}$ was added until reaching $\mathrm{pH} 2.5$, after which the amorphous powder was precipitated [47]. Form III of hydrochlorothiazide was obtained from an aqueous solution of sodium hydroxide by the addition of hydrochloric acid [48].

High-throughput crystallization method: A high-throughput process of crystal growth and analysis was developed by considering the different crystallization parameters [49]. Robotic liquid handling prepares individual solutions, which are subjected to various crystallization conditions. Crystals are screened by a combination of optical image analysis and Raman spectroscopy to differentiate polymorphs. The analysis of patterns of polymorph generation under a multitude of crystallization conditions provides a road map for generating the desired form. This technique is basically a robotic technique and has the advantage that polymorph screening is done online and any polymorphic transformation can be recorded directly.

Capillary growth method: This technique involves crystallization in small capillaries. Using this technique, a number of solvents can be screened for polymorph generation at once. It has been reported in the literature that to obtain metastable forms of a compound, a high super-saturation ratio is often required. Crystallization in capillaries is ideal for providing an environment with high super-saturation, because small volumes of solution isolate heterogeneous nucleants [50] and induce turbulence and convection. The other additional advantage of this approach is that the crystals can be analyzed by powder X-ray diffraction (PXRD) and single crystal X-ray diffraction.

Laser-induced nucleation: Non-photochemical laserinduced nucleation (NPLIN) is a crystallization technique which has the potential to affect the nucleation rate and therefore can generate new polymorphs. Initial experiments revealed a dramatic increase in the nucleation rate for a supersaturated urea solution, which was irradiated with plane polarized light [51]. The mechanism is proposed to occur by alignment of the pre-nucleating clusters in the applied optical field. This technique has not yet been used in pharmaceuticals, but it represents a promising area in the generation and discovery of new polymorphs.

Polymer heteronucleation: This is the first combinational approach for controlling polymorphism that directly targets nucleation. In this method, compounds are crystallized in the presence of chemically diverse polymer hetero-nuclei by solvent evaporation, cooling, sublimation or other traditional crystallization techniques. The polymer acts as an additional diverse element to affect the crystallization. This technique is useful for controlling the formation of established forms as well as for the discovery of unknown polymorphs without prior knowledge of the solid-state structure. This technique is mostly used for isolating protein molecules. Carbamazepine is known to have three polymorphs. However, a fourth polymorph [52] was discovered using polymer hetero-nucleation, which remarkably, proved to be more stable than the well-studied trigonal form [53].
Aitipamula et al. [54] clearly summarized the difference of crystalline, amorphous and co-crystal. The article defines the various regulatory compliance which are necessary for final drug launch having polymorphism. Not only had the above mentioned techniques now a days protein-mediated polymorphism through invertebrate calcium carbonate skeletal elements alone in the absence of additives such as $\mathrm{Mg}$ (II) can be done. In other words, certain proteins have inherent capabilities for nucleation and specific polymorph [55].

Techniques for the characterization of polymorphs: New polymorphs obtained using the above methods can be characterized by a range of analytical methods. Once a polymorph is isolated, it becomes necessary to identify and characterize it. The widely used analytical techniques are crystallography, microscopy, thermal analysis, solubility studies, vibrational spectroscopy and nuclear magnetic resonance. For compounds of pharmaceutical interest, X-ray diffraction is used to study polymorphic variations and all other techniques are considered to be supporting techniques. Although, techniques such as DSC, TGA, etc. are important tools to confirm the results, PXRD provides the most characteristic analysis of a polymorph, similar to NMR provides characteristics of compounds. An individual, defined polymorph will have a defined PXRD pattern.

Differential scanning calorimetry (DSC): Differential scanning calorimetry is the most commonly used technique in the pharmaceutical industry to study the phase transitions through which a compound undergoes during polymorphic transformations. This technique was first reported by Haines and Wilburn [56]. In this technique, the difference in the amount of heat required to increase the temperature of the sample and a reference are measured as a function of temperature [57,58] and a graph is plotted between the differential heating rate and temperature. The area under the curve in the obtained graph is directly proportional to the heat absorbed or evolved by the thermal event. The integration of these peaks thus gives the heat of reaction.

There are two basic types of differential scanning calorimeters, heat flux DSC and power compensation DSC. In a heat flux calorimeter, heat is transferred to the sample and reference through an alloy disk. The heat transported to the sample and reference is controlled, while the instrument monitors the temperature difference between the two. In power compensated calorimeters, separate heaters are used for the sample and the reference. Both the sample and the reference are maintained at the same temperature, while the electrical power used by their heaters is monitored.

The sample pans in both the techniques are designed to have a high thermal conductivity. The condensed sample, such as a powder or crystal, is generally placed in an aluminum sample pan, which is then placed in the sample cell. Before analysis, a baseline is measured. Sample sizes generally range from 3-5 mg and are crimped in an aluminum pan by a welding press. The reference consists of a crimped empty aluminum pan that is placed in the reference cell of the instrument. The analytical time is dependent on the heating rate and heating range. The effect of different heating rates during DSC was studied by Lang et al. [59] which clearly showed the effect of temperature on polymorph synthesis. 
In DSC measurements, an exothermic reaction is plotted as a positive thermal event, whereas an endothermic reaction is plotted as a negative thermal event. Fig. 2 shows a typical DSC curve for an amorphous compound, which first undergoes a glass transition at temperature $T_{g}$ and then crystallization at temperature $T_{c}$ in an exothermic process. As the temperature increases, the sample begins to melt and exhibits an endothermic peak at temperature $\mathrm{T}_{\mathrm{m}}$. Therefore, the DSC method can be used to determine the melting point of different polymorphs [60]. As different polymorphs of the same compound have different melting points and undergo different thermal events, they produce different DSC curves.

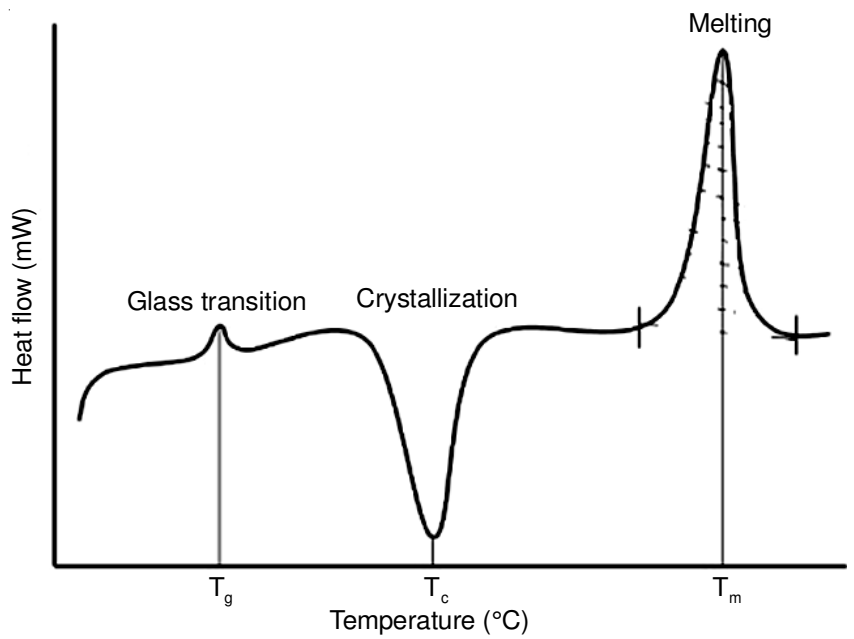

Fig. 2. Illustration of different thermal events in a typical DSC curve

The DSC curves of two forms of iopanoic acid, Form I and Form II, are shown in Fig. 3. The DSC curve of Form II shows an additional endothermic peak at $139{ }^{\circ} \mathrm{C}$, which is absent in the curve of Form I. The second peak might be due to the removal of solvent from the polymorph.

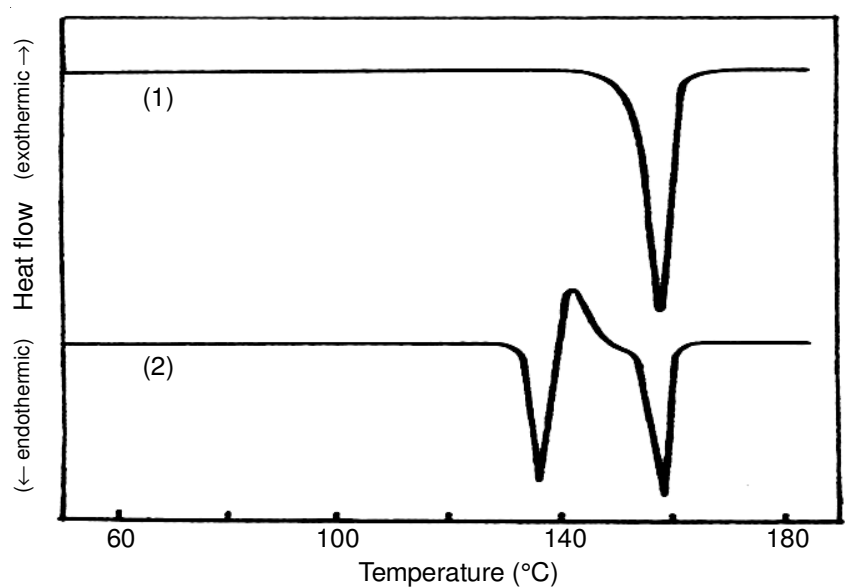

Fig. 3. DSC curves of iopanoic acid: (1) Form I and (2) Form II

Thermal gravimetric analysis: Thermal gravimetric analysis (TGA) is a measure of the thermally induced weight loss of a material as a function of the applied temperature. This method is most commonly used to study desolvation processes and compound decomposition, as these processes are accompanied by weight change and can thus be identified by a TG weight loss over the same temperature range. The higher the decomposition temperature of a given compound, the greater its stability. On the other hand, solid-liquid and solid-solid phase transformations, in which the DSC method is used, are not accompanied by mass loss of the sample and would not register in a TG thermogram. Thermal-gravimetric analysis is also used to determine the total volatile content in a solid and thus helps to distinguish solvates or hydrates from anhydrous compounds.

This technique was first used by Honda in 1915 to study manganese oxysalts [61] and consists of continuous recording of the mass of the sample as it is heated in a furnace. The most common weighing device is a microbalance, which permits the characterization of milligram $(\mathrm{mg})$ quantities of samples. The crucible in which the sample is placed is usually made of platinum because of its high melting point $\left(1772{ }^{\circ} \mathrm{C}\right)$ and low reactivity. If a reaction with platinum is possible, a crucible made of aluminum (melting point: $660^{\circ} \mathrm{C}$ ) or silica (melting point: $1410^{\circ} \mathrm{C}$ ) can be used. The TGA curves (thermograms) of (S)-4-[[[1-(4-flurorophenyl)-3-(1-methylethyl)-1-indol-2yl]-hydroxyphosphinyl]-3]-hydroxybutanoic acid disodium salt (Fig. 4) are shown at $3 \%, 33 \%, 52 \%, 60 \%$ and $75 \%$ humidity [62].

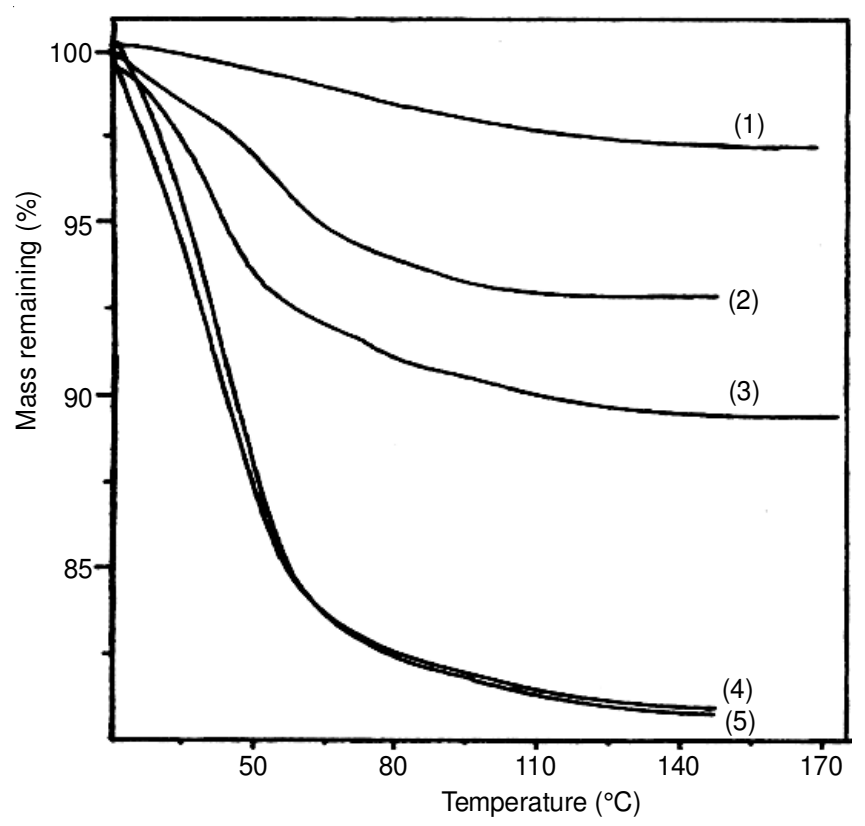

Fig. 4. Thermograms of (S)-4-[[[1-(4-flurorophenyl)-3-(1-methylethyl)-1indol-2-yl]-hydroxyphosphinyl]-3]-hydroxybutanoic acid disodium salt

X-ray diffraction: Polymorphism ordinarily arises from differences in the packing of conformationally equivalent or in equivalent molecules. The three-dimensional pattern of atoms in a crystalline solid is capable of acting as a diffraction grating to light with a wavelength of the same order of magnitude as the translational repeat period of the molecular pattern. This period is of the order of $10^{-10} \mathrm{~m}$ and light with a wavelength of this magnitude is called X-ray radiation. All X-ray diffraction techniques are based on Bragg's Law, which describes the diffraction of a monochromatic X-ray beam impinging on a plane of atoms. According to Bragg's Law

$$
\mathrm{n} \lambda=2 \mathrm{~d} \sin \theta
$$


where $\mathrm{n}$ is the order of the reflection $(\mathrm{n}=1,2,3 \ldots), \lambda$ is the wavelength in $\AA$, $d$ is the interatomic spacing between the crystal planes in $\AA$ (the d-spacing) and $\theta$ is the angle of incidence of the X-ray and crystal plane. The relative intensities of the diffracted angle is equal to the number of free and independent electrons scattering the X-ray beam. As different polymorphs have different molecular arrangements within the crystal lattice, they give different diffraction patterns. There are two types of X-ray diffraction techniques used to determine the polymorphism in compounds.

Single crystal X-ray: The technique of single crystal Xray crystallography has three basic steps. The first and often most difficult step is to obtain an adequate crystal of the material under study. The crystal should be sufficiently large (typically larger than $0.1 \mathrm{~mm}$ in all dimensions), pure in composition and regular in structure, with no significant internal imperfections such as cracks or twinning.

In the second step, the crystal is placed in an intense beam of X-rays, usually of a single wavelength (monochromatic $\mathrm{X}$-rays), producing a regular pattern of reflections. As the crystal is gradually rotated, previous reflections disappear and new ones appear; the intensity of each spot is recorded at each orientation of the crystal. Multiple data sets may have to be collected, with each set covering slightly more than half a full rotation of the crystal and typically containing tens of thousands of reflections.

In the third step, these data are combined computationally with complementary chemical information to produce and refine a model of the atomic arrangement within the crystal. The final, refined model of the atomic arrangement, now called a crystal structure, is usually stored in a public database.

Though solving a crystal structure provides great insight into polymorphic solids, the necessity for obtaining suitable single crystals and the degree of complexity associated with data analysis precludes this technique from being used on a routine basis for batch crystallization. Most drug substances in the pharmaceutical industry are obtained as microcrystalline powders, from which it is very difficult to obtain a single crystal of the desired quality. Moreover, during the evolution of a drug substance, it is usually sufficient to establish only the polymorphic identity and to verify that the isolated compound is of the desired structure. For these reasons, single crystal XRD is not the most commonly used tool for the routine characterization of polymorphs and solvates. The single crystals of two morphs, Form I and Form II, of aspirin are shown in Fig. 5 [63].

Powder X-ray diffraction (PXRD): Powder X-ray diffraction is the most common technique used in the pharmaceutical industry for the characterization of polymorphs. A PXRD system consists of an X-ray source, two goniometers, a sample holder, a detector, a computer system and an optical element [64]. X-rays are generated by X-ray tube using copper (1.54 $\AA$ ) or molybdenum $(0.71 \AA)$ targets. This beam is then filtered by a nickel filter, for a beam generated by a copper target, or by a zirconium filter, for a beam generated by a molybdenum target, before contacting the crystal sample. The X-rays reflected from the sample are then filtered by another filter before reaching the detector. The two goniometers are used to change
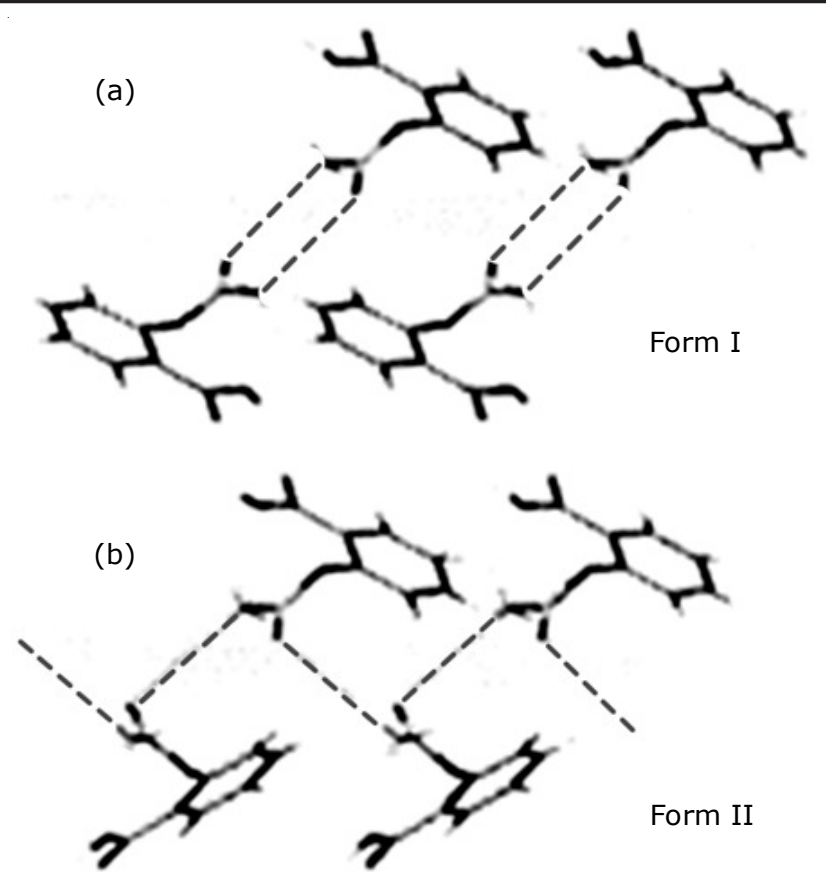

Fig. 5. Single crystal of aspirin: a) Form I and b) Form II

the incident $X$-ray angle $(\theta)$ for the source and the reflecting X-ray angle (20) for the detector. Approximately 80-100 mg of sample is used in the analysis. To measure the powder pattern, a randomly oriented sample is prepared to expose all the plains of the sample. The scattering angle $\theta$ is measured by slowly rotating the sample and using a scintillation counter to measure the angle of diffracted X-rays with respect to the angle of the incident beam. Alternatively, the angle between the sample and source can be fixed and the detector is moved along the prescribed path to determine the angles of the scattered radiation. The PXRD pattern between the scattering angle $(2 \theta)$ and intensity (counts) thus consists of a series of peaks detected at characteristic scattering angles. These angles and their relative intensities can be correlated with the $\mathrm{d}$ spacing to obtain a complete crystallographic characterization of the powdered sample. The United States Pharmacopeia states that two polymorphs are said to be identical if the scattering angle of their 10 strongest reflections agree within $\pm 0.2^{\circ}$ and if the relative intensities of these reflections do not vary by more than $20 \%$, but this does not apply in the case of solvates or hydrates. If the patterns of a $100 \%$ crystalline and a $100 \%$ amorphous material can be established, then the integrated peak intensity of the analyte can be used to calculate the percentage of crystallinity. Typical PXRD patterns of theophylline in the metastable (M), anhydrous (I) and monohydrate (II) state are shown in Fig. 6 [65]. The metastable form shows the same peaks as the monohydrate form, except that the peaks are sharper in the latter. The anhydrous form shows a peak at a $2 \theta$ of approximately $7^{\circ}$, i.e. between $5-10^{\circ}$, which is absent in both the monohydrate and metastable forms.

Fig. 7 shows the PXRD pattern of the crystalline and amorphous forms of sucrose. The crystalline form shows sharp peaks, whereas the amorphous form does not show any peaks [66]. 


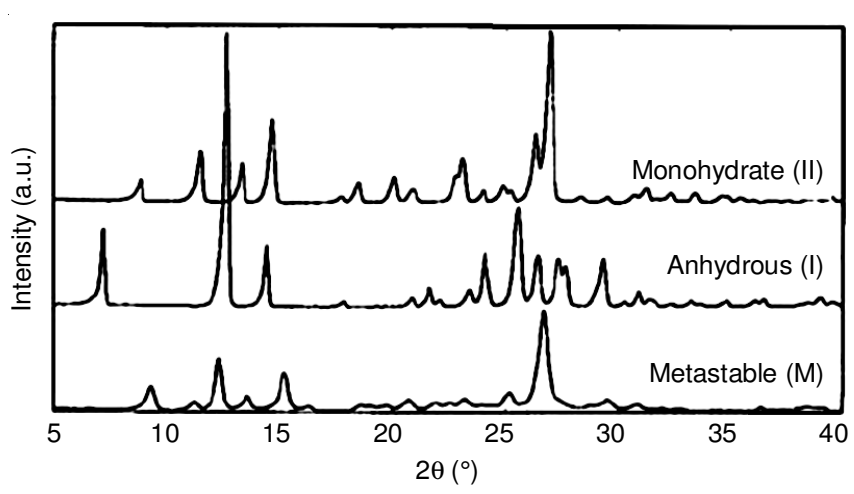

Fig. 6. Diffractograms of theophylline in the metastable (M), anhydrous (I) and monohydrate (II) phase

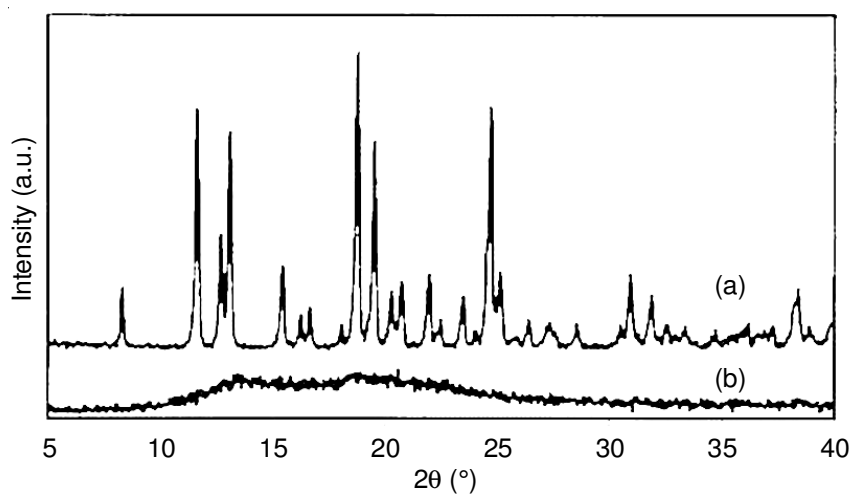

Fig. 7. (a) Crystalline (b) amorphous form of sucrose

The anhydrous and hydrate forms of moxifloxacin (Fig. 8) show different PXRD patterns over the $2 \theta$ range of $25-30^{\circ}$ [64]. Eight different PXRD patterns were shown by Lang et al. [66] for a drug for Sanofi Aventis.
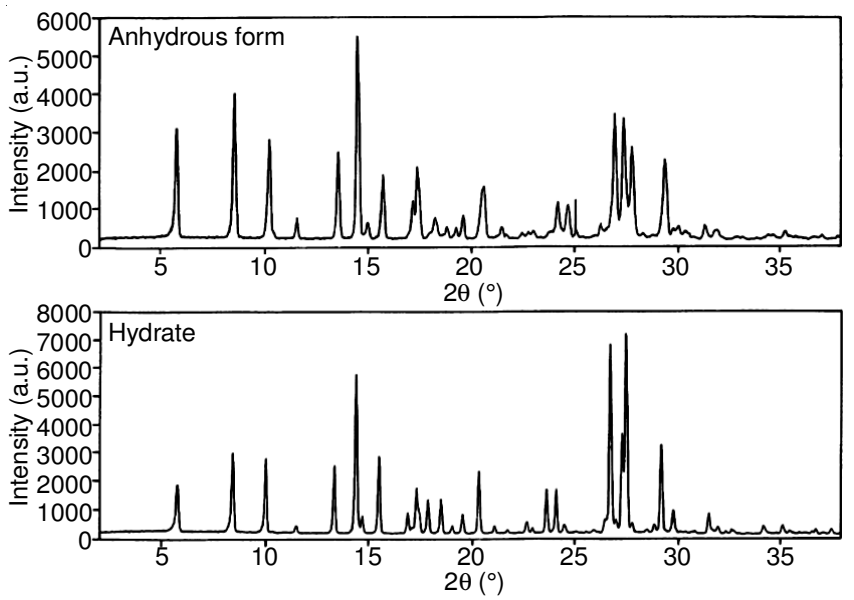

Fig. 8. Anhydrous and hydrate form of moxifloxacin

Microscopy: Microscopy is another important tool for the characterization of polymorphs and solvates. Since the crystal structures of different polymorphic forms are different, they give unique microscopic pictures. This technique can be divided into two types, namely, optical and electron microscopy. While optical microscopy is limited to $600 \times$ magnification, $90000 \times$ magnification is possible for electron microscopy. Each technique provides specific information. Substantial characterization of the polymorphic system can be accom- plished using two types of microscopic methods. Electron microscopy gives excellent topographic and shape information $[67,68]$. Optical microscopy can capture images of wet samples and therefore can be used for samples in solution. The time to obtain a good optical microscopy or electron microscopy image depends on experience and skill, varying from several minutes to much longer. Optical microscopy is not a destructive method and thus, the sample can be recovered after analysis. In this method, an amorphous sample shows dark patches, as it does not reflect light, while a crystalline sample shows a coloured pattern. Therefore, optical microscopy is used to check for amorphicity in crystalline forms and vice versa. Optical microscopy images of (S)-4-[[[1-(4-flurophenyl)-3-(1-methyl-ethyl)1H-indol-2-yl]-ethnyl]-hydroxyphosphinyl]-3-]hydroxylbutanoic acid sodium salt at relative humidities of 11, 60, 75 and $84 \%$ are shown in Fig. 9 [69].
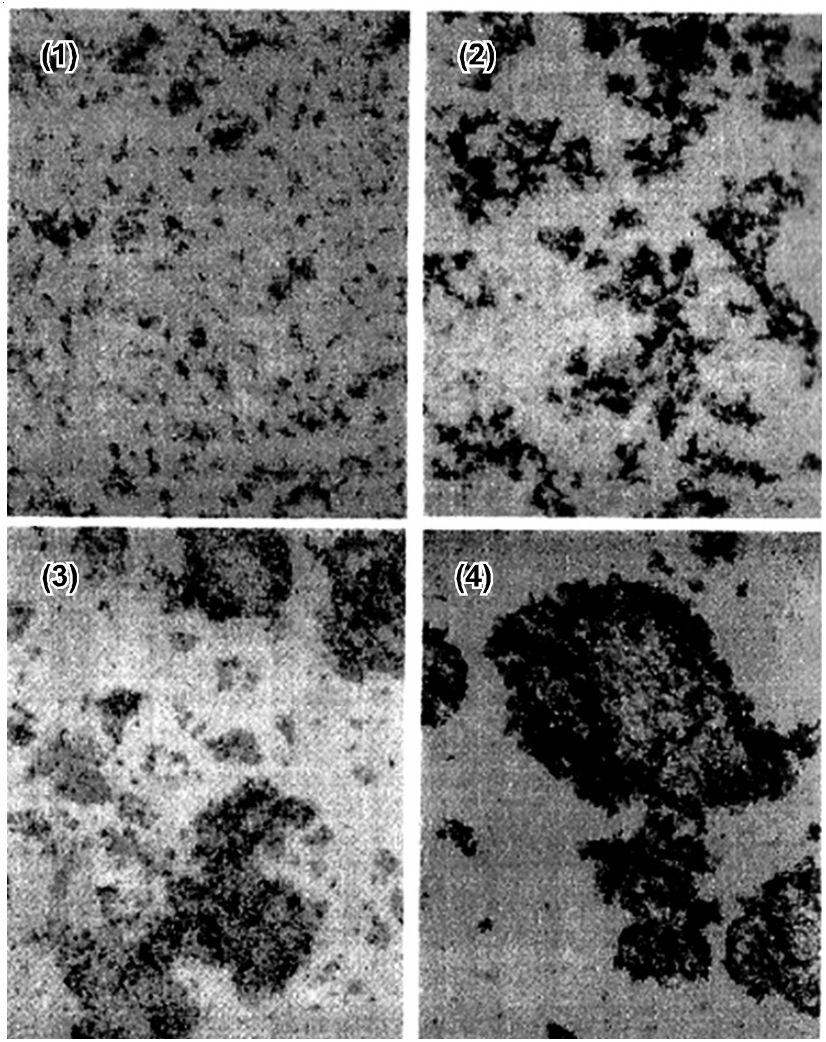

Fig. 9. Optical microscopy images of (S)-4-[[[1-(4-flurophenyl)-3-(1-methylethyl)-1H-indol-2-yl]-ethnyl]-hydroxyphosphinyl]-3-]hydroxylbutanoic acid sodium salt

Solid-state NMR (SSNMR): SSNMR spectroscopy is one of the most important analytical techniques for the determination of molecular structure [70]. Obtaining high-resolution spin-1/2 SSNMR spectra has become routine with the introduction and implementation of the cross polarization/magic angle spinning (CP/MAS) technique and hardware advances. The most widely used SSNMR technique for the structural characterization of food solids is ${ }^{13} \mathrm{C} \mathrm{CP} / \mathrm{MAS}$ NMR spectroscopy. SSNMR spectra of crystalline materials often feature sharp resonances at chemical shifts characteristic of the molecular and crystal structure. This technique is also used for the study of conformational polymorphism because small changes in conformation and local electronic structure could cause obser- 
vable differences in chemical shifts [71,72]. Different crystal forms can have relatively large changes in some chemical shift resonances [73]. A literature survey reveals the use of SSNMR spectroscopic data with PXRD. In the case of neotame polymorphs [74], the existence of seven polymorphic forms could be confirmed with the SSNMR technique. In this case, PXRD could not detect the conformational polymorphs.

SSNMR also provides information about molecular dynamics [75]. Although molecular motions can be studied using anisotropic displacement parameters from PXRD, the technique are limited to motions that are comparatively fast (about $10^{-18} \mathrm{~s}$ ). Therefore, slow dynamic processes cannot be distinguished from static disorder in molecular solids using diffraction techniques. SSNMR methods complement X-ray methods, as the former allows the study of a wide range of time scales (about $10^{-2}$ to $10^{-10} \mathrm{~s}$ ) over which molecular motions occur. The solid-state NMR spectrum of Form I of benoxaprofen is shown in Fig. 10. The NMR spectrum of the completely decoupled solution phase shows all individual peaks, whereas the NMR spectrum of Form I shows unresolved broad peaks between 100-150 ppm [76].

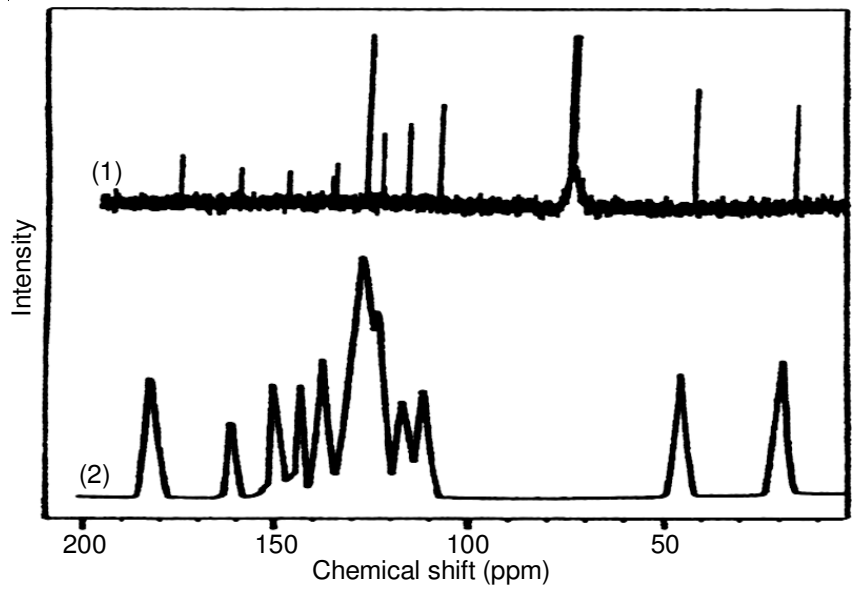

Fig. 10. Solid-state NMR spectra of the 1) completely decoupled solution phase and 2) Form I of benoxaprofen

Fourier transform infrared spectroscopy: Fourier transform infrared (FT-IR) spectroscopy combines the advantage of IR spectroscopy and Fourier transformation to allow the identification of the molecular vibrations and bending of organic functional groups. Fourier transform improves the throughput of the instrument and much greater signal-to-noise ratios are observed [77]. It also decreases the analysis time. In most cases, a good spectrum can be collected in 1-2 min. FTIR spectroscopy is a low-cost, easy-to-use and well-understood technique. The IR beam used in FT-IR is passed through a Michelson interferometer to maintain the intensity of the IR source and then through the sample to cause IR absorption [78]. After the detector receives the IR signal, the optical process is finished. This electronic process is combined with Fourier transformation, named after Jean-Baptiste Joseph Fourier, who converted time-based signals (described as a series of sinusoidal terms) into the frequency domain.

The spectrum is specific to each molecule and can identify the functional groups in a sample. The solid spectra of many polymorphic systems, such as tegafur [79], etoposide [80] and carbamazepine [81], have been found to differ only slightly, indicating that the molecular vibration pattern is not appreciably affected by differences in the crystal structure, whereas for ranitidine hydrochloride [82] and mexiletine hydrochloride [83], an appreciable change in the IR frequencies was observed. FT-IR spectroscopy is a widely used technique for the characterization of solvates. As solvent molecules are incorporated in the crystal lattice, the solvated structure becomes sufficiently different from the anhydrous form. Studies carried out in the high-energy region of the infrared spectra yields spectral differences between solvated phase and the anhydrous phase. When water acts as a solvation agent, the frequencies at 3600-3100 $\mathrm{cm}^{-1}$ are found to be mostly affected, as observed in the case of digoxin [84], ampicillin [85] and trazodone hydrochloride [86]. Organic solvents also induce appreciable changes in the high-energy spectral region. The IR spectra of the methanolsolvated form and anhydrous Form I of 9,10-anthraquinone are shown in Fig. 11. The solvated phase shows sharp peaks, whereas the anhydrous phase shows broad peaks.

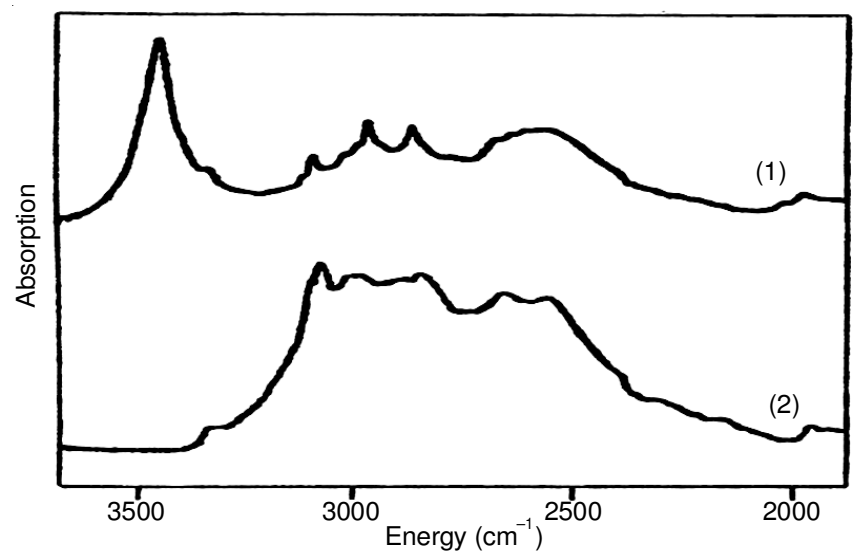

Fig. 11. IR spectra of 9,10-anthraquinone: 1) methanol-solvated form and 2) anhydrous Form I

Raman spectroscopy: Raman spectroscopy also records the vibrational modes of a compound by measuring the inelastic scattering of radiation by a non-absorbing medium [87]. When a beam of light is passed through a compound, approximately all photons are scattered with a loss or gain in energy. Inelasticity scattered radiations can occur at lower (Stokes lines) and higher (anti-Stokes lines) frequencies relative to that of the incident light. The energy displacements relative to the energy of the incident beam correspond to the vibrational transition frequencies of both media. For high-frequency vibrations, the Stokes lines are intense relative to the anti-Stokes lines. Raman spectra make exclusive use of the Stokes component. Therefore, Raman scattering bands are quite sharp. The Raman spectra of fluconazole in Form I and Form II show a difference above $3000 \mathrm{v}$. In Form II, the peak exists as a single peak, while in Form I, two peaks are observed (Fig. 12) [88]. Raman spectroscopic studies were also done on Difunisal Form I-IV to deeply understand the crystallization pattern [89]. Computer simulations have also played an important role in polymorph predictions [90].

\section{Conclusion}

The techniques described above are used not only to identify and characterize new morphs but to resolve mixtures of 


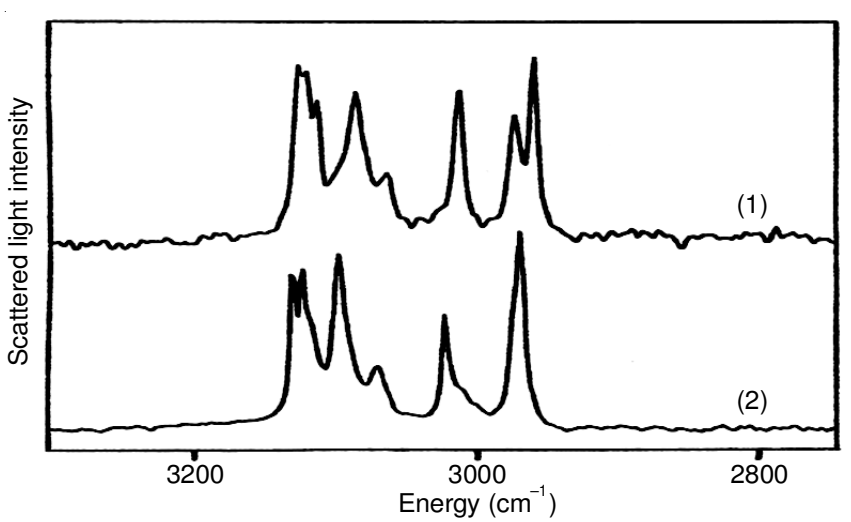

Fig. 12. Raman spectra of fluconazole: 1) Form I and 2) Form II

morphs. For example, a slow PXRD scan can be run to identify the characteristic peaks of a certain morph in a mixture of morphs. DSC clearly depicts the morph by showing two endotherms in the case of solvates/hydrates. TGA also shows weight loss in the case of solvates/hydrates. The most commonly used techniques are PXRD, DSC and TGA, while single crystal and solid-state NMR are used as specialized techniques in some large pharmaceutical companies.

\section{ACKNOWLEDGEMENTS}

The authors hereby acknowledge IIS and Rajasthan University, Jaipur for their support.

\section{REFERENCES}

1. A.C. Zettlemoyer and M. Dekker, Nucleation, Marcel Dekker, New York (1969).

2. N. Rodriguez-Hornedo and D. Murphy, J. Pharm. Sci., 88, 651 (1998); https://doi.org/10.1021/js980490h.

3. J.W. Mullin, Crystallization, Butterworth-Hienemann, Oxford (1992).

4. A. Myerson, Handbook of Industrial Crystallization, ButterworthHeinemann, Boston (2002)

5. L.J. Chyall, J.M. Tower, D.A. Coates, T.L. Houston and S.L. Childs, Cryst. Growth Des., 2, 505 (2002); https://doi.org/10.1021/cg0200311.

6. L.S. Taylor and G. Zografi, Pharm. Res., 14, 1691 (1997); https://doi.org/10.1023/A:1012167410376.

7. M.D. Ward, Chem. Rev., 101, 1697 (2001); https://doi.org/10.1021/cr000020j.

8. M. Lang, A.L. Grzesiak and A.J. Matzger, J. Am. Chem. Soc., 124, 14834 (2002); https://doi.org/10.1021/ja0286526.

9. N. Rodríguez-Hornedo and D. Murphy, J. Pharm. Sci., 93, 449 (2004); https://doi.org/10.1002/jps.10496.

10. D. Murphy, F. Rodriguez-Cintron, B. Langevin, R.C. Kelly and N. Rodriguez-Hornedo, Int. J. Pharm., 246, 121 (2002); https://doi.org/10.1016/S0378-5173(02)00358-7.

11. N. Rodríguez-Hornedo, D. Lechuga-Ballesteros and H.-J. Wu, Int. J. Pharm., 85, 149 (1992); https://doi.org/10.1016/0378-5173(92)90144-Q

12. B. Rodriguez-Spong, C.P. Price, A. Jayasankar, A.J. Matzger and N. Rodriguez-Hornedo, Adv. Drug Deliv. Rev., 56, 241 (2004); https://doi.org/10.1016/j.addr.2003.10.005.

13. Y. Suzuki, Bull. Chem. Soc. Jpn., 47, 2549 (1974); https://doi.org/10.1246/bcsj.47.2549.

14. R.J. Behme, T.T. Kensler and D.G. Mikolasek, Process for Buspirone Hydrochloride Polymorphic Crystalline form Conversion, US Patent 4810789 (1989).

15. F. Kaneko, H. Sakashita, M. Kobayashi and M. Suzuki, J. Phys. Chem., 98, 3801 (1994); https://doi.org/10.1021/j100065a041.
16. N. Garti, E. Wellner and S. Sarig, Kristall Tech., 15, 1303 (1980); https://doi.org/10.1002/crat.19800151112.

17. M.C. Martínez-Ohárriz, C. Martín, M.M. Goñi, C. Rodríguez-Espinosa, M.C. Tros De Ilarduya-Apaolaza and M. Sánchez, J. Pharm. Sci., 83, 174 (1994); https://doi.org/10.1002/jps.2600830212.

18. L.-S. Wu, G. Torosian, K. Sigvardson, C. Gerard and M.A. Hussain, J. Pharm. Sci., 83, 1404 (1994); https://doi.org/10.1002/jps.2600831008

19. M. Kitamura, H. Furukawa and M. Asaeda, J. Cryst. Growth, 141, 193 (1994); https://doi.org/10.1016/0022-0248(94)90112-0.

20. L.C. Chang, M.R. Caira and J.K. Guillory, J. Pharm. Sci., 84, 1169 (1995); https://doi.org/10.1002/jps.2600841007.

21. J. Caplette, T. Frigo, M. Jozwiakowski, H. Shea, M. Mirmehrabi and P. Müller, Int. J. Pharam., 527, 42 (2017); https://doi.org/10.1016/j.ijpharm.2017.05.031.

22. Y. Kumar, R.K. Thaper and S.M. Dileep Kumar, Process for the Production of Amorphous Atorvastatin Calcium, US Patent 6528660 (2003).

23. C.A. Briggs, K. Harasawa, S. Ichikawa, R.A. Jennings, K. Minohara, S. Nakagawa and R.A. Wade, Crystalline Forms of $\left[R-\left(R^{*}, R^{*}\right)\right]-2-(4-$ fluorophenyl)- $\beta, \delta$-dihydroxy-5-(1-methylethyl)-3-phenyl-4-[(phenylamino)carbonyl]-1H-pyrrole-1-heptanoic acid hemi calcium salt (Atorvastatin), EP0848705 (2001).

24. M. Otsuka, M. Onoe and Y. Matsuda, Drug Dev. Ind. Pharm., 20, 1453 (1994); https://doi.org/10.3109/03639049409038382.

25. N. Kaneniwa, M. Otsuka and T. Hayashi, Chem. Pharm. Bull. (Tokyo), 33, 3447 (1985); https://doi.org/10.1248/cpb.33.3447.

26. A. Saleki-Gerhardt, J.G. Stoweell, S.R. Byrn and G. Zografi, J. Pharm. Sci., 84, 318 (1995); https://doi.org/10.1002/jps.2600840311.

27. Y. Fukumori, T. Fukuda, Y. Yamamoto, Y. Shigitani, Y. Hanyu, Y. Takeuchi and N. Sato, Chem. Pharm. Bull. (Tokyo), 31, 4029 (1983); https://doi.org/10.1248/cpb.31.4029.

28. Y. Kawashima, T. Niwa, H. Takeuchi, T. Hino, Y. Itoh and S. Furuyama, J. Pharm. Sci., 80, 472 (1991); https://doi.org/10.1002/jps.2600800515.

29. H.G. Brittain, K.R. Morris, D.E. Bugay, A.B. Thakur and A.T. Serajuddin, J. Pharm. Biomed. Anal., 11, 1063 (1993); https://doi.org/10.1016/0731-7085(93)80083-D

30. M. Otsuka, K. Otsuka and N. Kaneniwa, Drug Dev. Ind. Pharm., 20, 1649 (1994); https://doi.org/10.3109/03639049409050205.

31. J. Pirttimäki, E. Laine, J. Ketolainen and P. Paronen, Int. J. Pharm., 95, 93 (1993); https://doi.org/10.1016/0378-5173(93)90394-U.

32. N. Chieng, T. Rades and D. Saville, Eur. J. Pharm. Biopharm., 68, 771 (2008); https://doi.org/10.1016/j.ejpb.2007.09.001.

33. S.P. Duddu and K. Weller, J. Pharm. Sci., 85, 345 (1996); https://doi.org/10.1021/js950376o.

34. O. Funk, L. Schwabe and K.-H. Froemming, Pharmazie, 48, 745 (1993).

35. G. Bettinetti, A. Gazzaniga, P. Mura, F. Giordano and M. Setti, Drug Dev. Ind. Pharm., 18, 39 (1992); https://doi.org/10.3109/03639049209043682.

36. S.Y. Tsai, S.C. Kuo and S.Y. Lin, J. Pharm. Sci., 82, 1250 (1993); https://doi.org/10.1002/jps.2600821213.

37. J. Fokkens, J. Van Amelsfoort, C. De Blaey, C. De Kruif and J. Wilting, Int. J. Pharm., 14, 79 (1983); https://doi.org/10.1016/0378-5173(83)90116-3.

38. M. Sakiyama and A. Imamura, Thermochim. Acta, 142, 365 (1989); https://doi.org/10.1016/0040-6031(89)85032-4.

39. M. Yoshioka, B.C. Hancock and G. Zografi, J. Pharm. Sci., 83, 1700 (1994); https://doi.org/10.1002/jps.2600831211.

40. J. Gómez-Morales, Á. Hernández-Hernández, G. Sazaki and J.M. García-Ruiz, Cryst. Growth Des., 10, 963 (2010); https://doi.org/10.1021/cg901279t.

41. A.S. Rankell, H.A. Liebermann and R.F. Schiffman, in: H. Lieberman and L. Lachman (Eds.), The Theory and Practice of Industrial Pharmacy, Lea \& Feabiger, Philadelphia, pp. 47 (1986). 
42. L.-E. Briggner, G. Buckton, K. Bystrom and P. Darcy, Int. J. Pharm., 105, 125 (1994); https://doi.org/10.1016/0378-5173(94)90458-8.

43. N.E. Digoxin, B. Dolle and J.M. Bafort, Pharm. Ind., 44, 630 (1982).

44. T. Sato, M. Ishiwata and S. Nemoto, Yakuzaigaku, 49, 93 (1989).

45. M.J. Pikal, A.L. Lukes, J.E. Lang and K. Gaines, J. Pharm. Sci., 67, 767 (1978); https://doi.org/10.1002/jps.2600670609.

46. Y. Matsuda, M. Otsuka, M. Onoe and E. Tatsumi, J. Pharm. Pharmacol., 44, 627 (1992);

https://doi.org/10.1111/j.2042-7158.1992.tb05483.x.

47. W.C. Stagner and J.K. Guillory, J. Pharm. Sci., 68, 1005 (1979); https://doi.org/10.1002/jps.2600680823.

48. B.H. Kim and J.K. Kim, Arch. Pharm. Res., 7, 47 (1984); https://doi.org/10.1007/BF02856921.

49. M.L. Peterson, S.L. Morissette, C. McNulty, A. Goldsweig, P. Shaw, M. LeQuesne, J. Monagle, N. Encina, J. Marchionna, A. Johnson, J. GonzalezZugasti, A.V. Lemmo, S.J. Ellis, M.J. Cima and Ö. Almarsson, J. Am. Chem. Soc., 124, 10958 (2002); https://doi.org/10.1021/ja020751w.

50. J.H. Perepezko, Mater. Sci. Eng. A, 178, 105 (1994); https://doi.org/10.1016/0921-5093(94)90527-4.

51. B.A. Garetz, J.E. Aber, N.L. Goddard, R.G. Young and A.S. Myerson, Phys. Rev. Lett., 77, 3475 (1996); https://doi.org/10.1103/PhysRevLett.77.3475.

52. M.D. Lang, J.W. Kampf and A.J. Matzger, J. Pharm. Sci., 91, 1186 (2002); https://doi.org/10.1002/jps.10093.

53. A.L. Grzesiak, M. Lang, K. Kim and A.J. Matzger, J. Pharm. Sci., 92, 2260 (2003); https://doi.org/10.1002/jps.10455.

54. S. Aitipamula, R. Banerjee, A.K. Bansal, K. Biradha, M.L. Cheney, A.R. Choudhury, G.R. Desiraju, A.G. Dikundwar, R. Dubey, N. Duggirala, P.P. Ghogale, S. Ghosh, P.K. Goswami, N.R. Goud, R.R.K.R. Jetti, P. Karpinski, P. Kaushik, D. Kumar, V. Kumar, B. Moulton, A. Mukherjee, G. Mukherjee, A.S. Myerson, V. Puri, A. Ramanan, T. Rajamannar, C.M. Reddy, N. Rodriguez-Hornedo, R.D. Rogers, T.N.G. Row, P. Sanphui, N. Shan, G. Shete, A. Singh, C.C. Sun, J.A. Swift, R. Thaimattam, T.S. Thakur, R. Kumar Thaper, S.P. Thomas, S. Tothadi, V.R. Vangala, N. Variankaval, P. Vishweshwar, D.R. Weyna and M.J. Zaworotko, Cryst. Growth Des., 12, 2147 (2012); https://doi.org/10.1021/cg3002948.

55. J.S. Evans, Minerals, 7, 62 (2017); https://doi.org/10.3390/min7040062.

56. P.J. Haines and F.W. Wilburn, in:Thermal Analysis and Differential Scanning Calorimetry, Blackie Academic and Professional, New York, USA, pp. 63-89 (1995).

57. L. Yu, S.M. Reutzel and G.A. Stephenson, Pharm. Sci. Technol. Today, 1, 118 (1998); https://doi.org/10.1016/S1461-5347(98)00031-5.

58. E.V. Boldyreva, V.A. Drebushchak, I.E. Paukov, Y.A. Kovalevskaya and T.N. Drebushchak, J. Therm. Anal. Calorim., 77, 607 (2004); https://doi.org/10.1023/B:JTAN.0000038998.47606.27.

59. P. Láng, E. Várkonyi, J. Ulrich, P. Szabó-Révésza and Z. Aigner, Analysis, 102, 229 (2015).

60. M.L.P. Leitãomlleitao@ @i.uc.pt, J. Canotilho, M.S.C. Cruz, J.C. Pereira A.T. Sousa and J.S. Redinha, J. Therm. Anal. Calorim., 68, 397 (2002); https://doi.org/10.1023/A:1016023315613.

61. P.J. Haines and F.W. Wilburn, in:Thermal Methods of Analysis Principles, Blackie Academic and Professional, New York, pp. 95 (1995)

62. K.R. Morris, A.W. Newman, D.E. Bugay, S.A. Ranadive, A.K. Singh, M. Szyper, S.A. Varia, H.G. Brittain and A.T.M. Serajuddin, Int. J. Pharm., 108, 195 (1994); https://doi.org/10.1016/0378-5173(94)90128-7.

63. P. Vishweshwar, J.A. McMahon, M. Oliveira, M.L. Peterson and M.J. Zaworotko, J. Am. Chem. Soc., 127, 16802 (2005); https://doi.org/10.1021/ja056455b.
64. T.L. Threlfall, Analyst, 120, 2435 (1995); https://doi.org/10.1039/an9952002435.

65. K. Matsuo and M. Matsuoka, Cryst. Growth Des., 7, 411 (2007); https://doi.org/10.1021/cg060299i.

66. P. Láng, V. Kiss, R. Ambrus, G. Farkas, P. Szabó-Révész, Z. Aigner and E. Várkonyi, J. Pharm. Biomed. Anal., 84, 177 (2013); https://doi.org/10.1016/j.jpba.2013.06.002.

67. G. Salvetti, E. Tognoni, E. Tombari and G. Johari, Thermochim. Acta, 285, 243 (1996); https://doi.org/10.1016/0040-6031(96)02915-2.

68. A. Grunenberg and P. Bosche, Crystal Modification of CDCH a Process for its Preparation and Pharmaceutical Formulations Comprising this Modification, US Patent 5849752 (1998).

69. T.G. Rochow and E.G. Rochow, An Introduction to Microscopy by Means of Light, Electrons, X-rays or Ultrasound, Plenum Press, New York (1978).

70. A.S. Borisov, P. Hazendonk and P.G. Hayes, J. Inorg. Organomet. Polym. Mater., 20, 183 (2010); https://doi.org/10.1007/s10904-010-9358-5

71. J.R. Smith, W. Xu and D. Raftery, J. Phys. Chem. B, 110, 7766 (2006); https://doi.org/10.1021/jp056195k.

72. J.W. Lubach and E.J. Munson, ed: W.R. Hilfiker, Polymorphism in the Pharmaceutical Industry, Wiley, Weinheim, pp. 81-93 (2006).

73. T.J. Offerdahl, Pharm. Tech., 30, 24 (2006).

74. L.R. Chen, B.E. Padden, S.R. Vippagunta, E.J. Munson and D.J. Grant, Pharm. Res., 17, 619 (2000); https://doi.org/10.1023/A:1007533419711.

75. M. Szelagiewicz, C. Marcolli, S. Cianferani, A. Hard, A. Vit, A. Burkhard, M. Von Raumer, U. Hofmeier, A. Zilian, E. Francotte and R. Schenker, J. Therm. Anal. Calorim., 57, 23 (1999); https://doi.org/10.1023/A:1010184805966.

76. S.R. Byrn, G. Gray, R.R. Pfeiffer and J. Frye, J. Pharm. Sci., 74, 565 (1985); https://doi.org/10.1002/jps.2600740516.

77. D.A. Skoog, F.J. Holler and T.A. Nieman, Principles of Instrumental Analysis, Thomson Learnin, Mississippi (2001).

78. F. Rouessac and A. Rouessac, in:Infrared Apectroscopy, John Wiley \& Sons, London, pp. 170-173 (2001).

79. B.R. Jasti, J. Du and R.C. Vasavada, Int. J. Pharm., 118, 161 (1995); https://doi.org/10.1016/0378-5173(94)00325-Y.

80. T. Uchida, E. Yonemochi, T. Oguchi, K. Terada, K. Yamamoto and Y. Nakai, Chem. Pharm. Bull. (Tokyo), 41, 1632 (1993); https://doi.org/10.1248/cpb.41.1632.

81. M.M. Lowes, M.R. Caira, A.P. Lotter and J.G. Van der Watt, J. Pharm. Sci., 76, 744 (1987); https://doi.org/10.1002/ips.2600760914.

82. T.J. Cholerton, J.H. Hunt, G. Klinkert and M. Martin-Smith, J. Chem. Soc., Perkin Trans. 2, 1961 (1984); https://doi.org/10.1039/P29840001761.

83. A. Kiss and J. Répási, Analyst, 118, 661 (1993); https://doi.org/10.1039/AN9931800661.

84. S. Botha and D. Flanagan, Int. J. Pharm., 82, 195 (1992); https://doi.org/10.1016/0378-5173(92)90175-2.

85. H.G. Brittain, D.E. Bugay, S.J. Bogdanowich and J. Devincentis, Drug Dev. Ind. Pharm., 14, 2029 (1988); https://doi.org/10.3109/03639048809152001.

86. K. Sasaki, H. Suzuki and H. Nakagawa, Chem. Pharm. Bull. (Tokyo), 41, 325 (1993); https://doi.org/10.1248/cpb.41.325.

87. J.G. Graselli, M.K. Snavely and B.J. Bulkin, Chemical Applications of Raman Spectroscopy, John Wiley, New York (1981).

88. X.J. Gu and W. Jiang, J. Pharm. Sci., 84, 1438 (1995); https://doi.org/10.1002/jps.2600841210.

89. A.R. Pallipurath, F. Civati, J. Sibik, C. Crowley, J.A. Zeitler, P. McArdle and A. Erxleben, Int. J. Pharm., 528, 312 (2017); https://doi.org/10.1016/j.ijpharm.2017.06.020.

90. K. Higashi, K. Ueda and K. Moribe, Adv. Drug Deliv. Rev., 117, 71 (2016); https://doi.org/10.1016/j.addr.2016.12.001. 